\title{
PURPOSE-ORIENTED MODELLING OF THE LEARNING PROCESS WHEN USING PROTOTYPES
}

\author{
Schork, Stefan; Kirchner, Eckhard \\ Technische Universität Darmstadt
}

\begin{abstract}
Prototypes are often used as a tool in the product development process and their usage is advised in many guidelines, frameworks and product development methods. Those prototypes achieve different goals of which most relate to getting new insights and information about the product in development. For the development of those prototypes however, significantly less development methods are available compared to the number of methods for the development of products. Investigating the process of using a prototype leads to the idea that the main purpose of those prototypes is describable as learning about the product. This idea is elaborated further and followed by the introduction of the detailed process model for prototyping which is primarily based on the detailed process model for products. However, the purpose of the prototype differs from the purpose of the product which leads to some significant changes of the model. To give an example of a prototyping process, the development of a sensorintegrating elastic claw coupling is introduced and analysed. In addition, this paper discusses the question, how other product development models may be applied to the development of prototypes.
\end{abstract}

Keywords: Prototype Development Process, Process modelling, Design for X (DfX), Design process

\section{Contact:}

Schork, Stefan

Technische Universität Darmstadt

Institute for Product Development and Machine Elements

Germany

schork@pmd.tu-darmstadt.de 


\section{INTRODUCTION AND MOTIVATION}

Prototyping is an essential and often advised activity in the development process of new products. Prototypes are used to gain new insights about the product in development and are especially useful to handle unknown factors and ambiguity according to Leifer and Steinert (2014). Ulrich and Eppinger (1995) identified four main goals of prototyping: learning, communication, integration and milestones. To fulfil these goals, different types of prototypes are used, for example functional prototypes and geometric prototypes. They are classifiable on two independent axes being virtual or physical and focussed or complete prototypes according to Ulrich and Eppinger (1995). Even though prototypes are a useful tool in the product development process, there are, compared to the amount of product development models and methods, significantly less prototype development models and methods. Research regarding prototypes often discusses the use of prototypes and introduces strategies to decide, which type of prototype is adequate in certain situations, as for example the prototype-for- $X$ framework introduced by Menold et al. (2018). Camburn et al. (2013) discussed different choices developers have when developing prototypes, for example scaling, relaxing requirements or deciding whether to use virtual or physical prototypes. Based on this discussion they introduced a strategy to support the related decision making. Camburn et al. (2017) reviewed the state of the art in prototyping, collecting and describing different approaches to the use of prototypes concluding, among other factors, that value of information gained with prototypes should be investigated further. In contrast to strategies regarding the use of prototypes, the development of the prototype itself is still depending on a high level of intuition, creativity and personal knowledge. Boehmer et al. (2016) ascertained that so-called Makerspaces support the creativity of the developer and therefore are a way to increase the effectiveness of the prototyping process. To emphasise on the development of the prototype itself, Schork and Kirchner (2018b) introduced a method to identify essential aspects of the product in development, which should be tested with prototypes. This paper ties in with this approach to focus on the development of prototypes and discusses the value of the information gained when testing with prototypes.

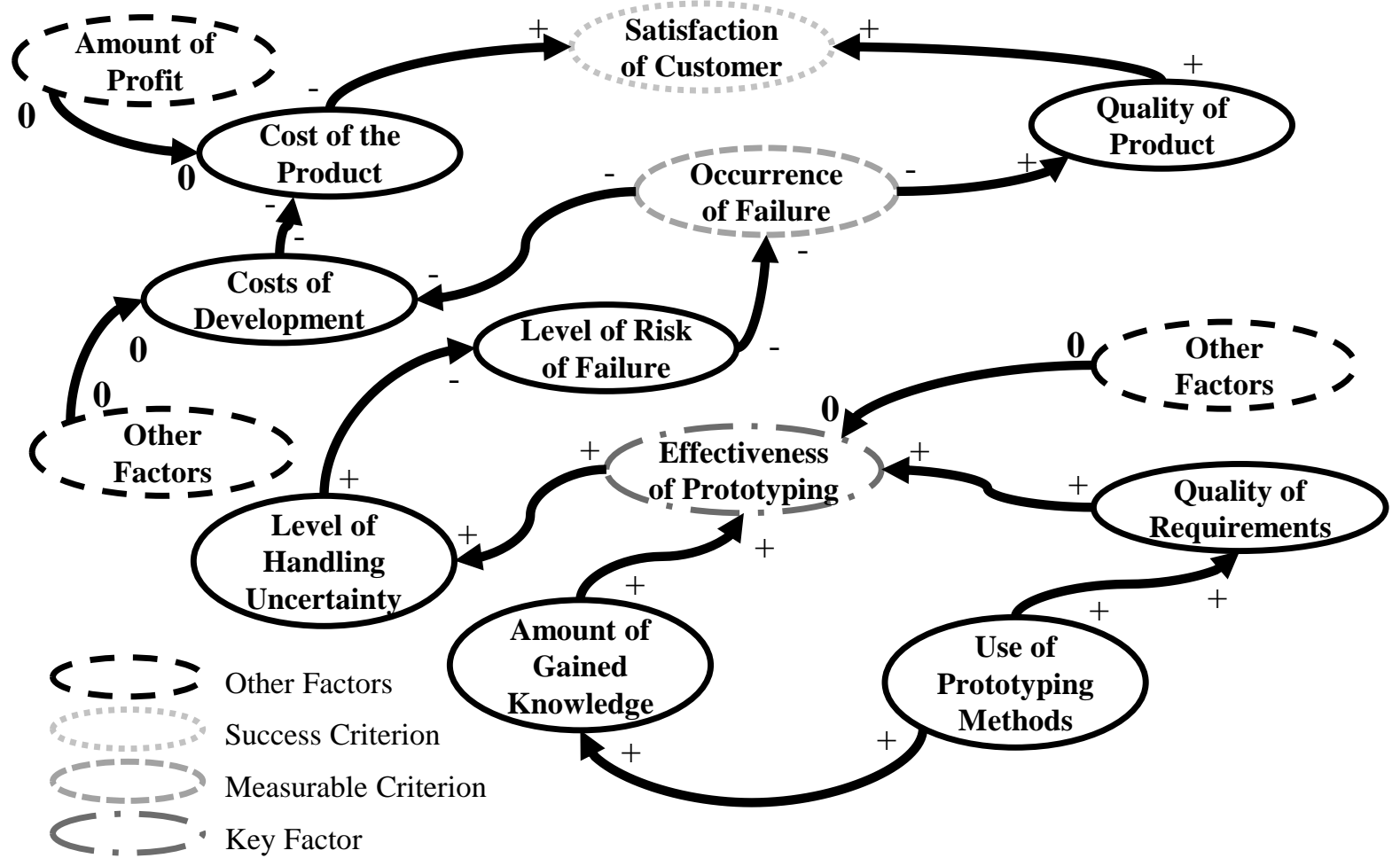

Figure 1. Partial intended impact model after Blessing and Chakrabarti (2009) showing the impact of prototyping methods on the satisfaction of the customer

\subsection{Aims and goals}

For this paper, the term prototype refers to every early version or representation of a product in development. This ranges from analytic equations and simulations over virtual models and physical 
functional samples up to nearly completed pre-series. The aim of the research topic in general is to increase the effectiveness of the prototyping process by providing usable models and methods to support the development of prototypes. The improved prototyping process ultimately leads to better products and a higher satisfaction of the customer. The goal of this paper therefore is to develop a model of the prototyping process based on which tools and methods for a methodical prototype development can be introduced.

The partial intended impact model shown in Figure 1 depicts the overall intended impact of the use of prototyping methods on the satisfaction of the customer. The key factor to the satisfaction of the customer in this representation is the effectiveness of the prototyping process. With an increasing amount of used prototyping methods, the amount of gained knowledge as well as the quality of requirements for the development of prototypes may increase. On the basis of constant other factors such as the available resources for prototyping or the prototyping environment, the factors stated above lead to an increase of the key factor. With a more effective prototyping the level of handling uncertainties is expected to increase, leading to a lower level of risk of failure and a decrease in the occurrence of failure which is a measurable criterion. With less failing products the product quality increases, which then satisfies the customer. Furthermore, fewer occurring failures reduce the costs of development. Again, keeping other factors, such as resource costs and the targeted profit constant, the cost of the product decreases, which also leads to a more satisfied customer. The satisfaction of the customer overall is the success criterion of the approach but in contrast to the occurrence of failures not directly measurable.

\subsection{Research question}

The research in this paper focusses on the usability and transferability of product development models to describe prototyping processes. The main research question is therefore stated as:

Which product development models can be transferred to describe the prototyping process?

To answer this research question, the development task when developing products is compared to the development task when developing prototypes to identify differences and similarities. Based on this comparison, product development models are adjusted to be used for prototype development.

\section{PROTOTYPES AS A MEANS TO AN END}

Heidemann (2001) concluded that products are only the means to fulfil a certain purpose which benefits the user. For the user, products have different benefits. The purpose the user needs the product for is describable as changing the state of an object from an unintended state to an intended state. For example, the main purpose of cars is to transport the user from one place to another. This means, that users do not buy cars because they want to have a car but they buy a car because they want to change their state from being at point A to being at point B. This approach leads to an objective based point of view of the product and the customer needs. When developing products, designers have to keep those user-needs in mind to develop a user-satisfying product. The user-needs - or the purposes of the product - therefore are a major development task, designers have to accomplish. To support designers in clarifying the development task and to define the purpose of a product as well as to identify requirements for the product based on the purpose of the product and the processes the user uses the product for, Heidemann (2001) developed the detailed process model.

\subsection{Comparing the development task of prototypes and products}

In some ways, products and prototypes are quiet similar. Schork and Kirchner (2018a) concluded, that the holistic prototype and process model in Figure 2 based on the holistic product and process model by Birkhofer et al. (2007) indicates viability. The core conclusion is that developers have to anticipate the life cycle of the prototype in a similar fashion as when developing the product. They are also able to influence the life cycle of prototypes with their design, especially regarding the prototype testing phase. The major difference concerns the development task. For products on the one hand the task is often driven by the purpose of the user. Prototypes on the other hand are mostly used to gather some kind of information so the development task for prototypes focusses on the amount of gained information and knowledge. To ensure, that the information gained with a prototype is usable, developers have to anticipate the prototype life cycle and the effects of changes between the product and the prototype. For instance, Hallmann et al. (2018) discussed the deviations caused by additive production principles and their dependency on the respective 
machine. The developer has to consider those properties when designing the prototype and has to factor these changes in when drawing conclusions from the prototype testing.

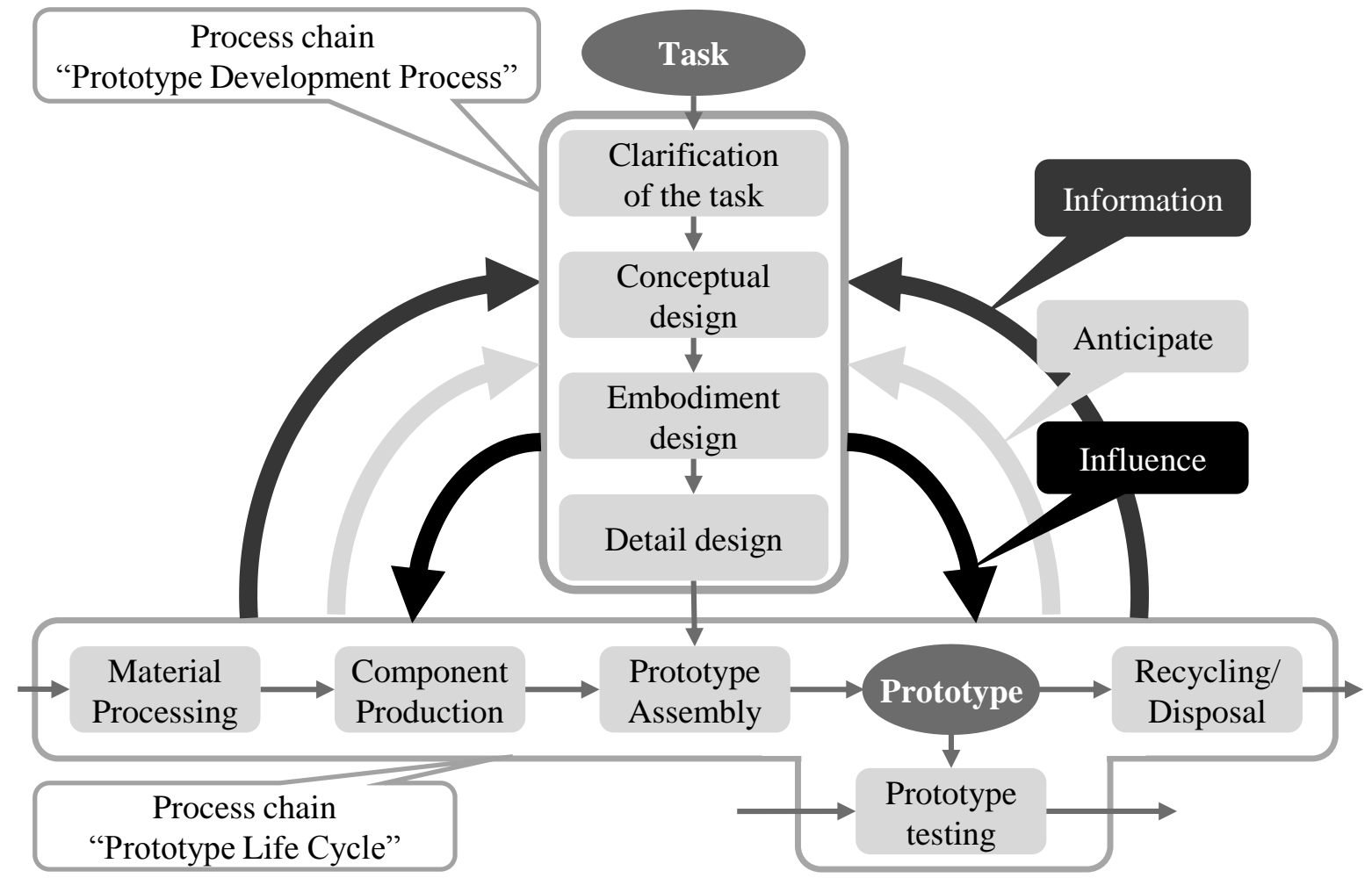

Figure 2. The holistic prototype and process model following Schork and Kirchner (2018a)

\subsection{The purpose of prototypes}

As explained in the introduction and motivation section Ulrich and Eppinger (1995) identified four main goals of prototyping, being learning, communication, integration and milestones. All of these goals have in common, that they are linked to some kind of information gathering process and the process of using these information to get new insights about the product. For learning, this thesis is quite self-explanatory meaning developers use prototypes in situations, in which their knowledge about the product is exceeded and they are not able to predict the outcome of a design decision. Therefore, developers have to learn about the product with the help of a prototype. This also reduces the possibility of misjudgements based on intuitive decision making described by Bursac et al. (2017). For communication, a similar explanation seems viable. In this case, developers use prototypes to support the communication for example with the management, the customer or user, all of which are sources of requirements for the product. Developers therefore use the prototype to learn about the needs and wishes of the different stakeholders. A comparable analysis is possible with integration. Prototypes of this category help developers to gain insights about how the product may behave in its environment. This also comes down to a learning process about the different influencing factors the environment has on the prototype and vice versa. The last category, milestones, is somewhat different in terms of learning. In this category, prototypes act as milestones in the development process, for example, to show the overall feasibility of a concept in an early stage of the development process. So the main purpose of the prototype is to indicate the maturity of the product. Still, there is some information to be gathered, based upon which the development team may learn about the product. In this case, the information is strongly related to the goals of the milestones. Overall, all four main goals found by Ulrich and Eppinger (1995) consist to a certain degree of gathering information in conjunction with learning about the product.

Menold et al. (2018) define in their Prototype-for-X Framework three prototyping activities, which describe different goals of the prototyping process. In their work, they introduce prototype for viability, prototype for feasibility and prototype for desirability. Prototypes for viability are used to decide if the product is within the time and budget constraints of the project. Feasibility describes functionality of the product in a technical way and prototyping for desirability should be used to 
gather user feedback, to determine if users would buy the product or not. Generalizing those approaches, they all try to answer questions about the product such as "Does the product fit into our time and budget constraints?", "Does the product function as intended?" or "Is this the product the user needs and wants?".

Matthiesen et al. (2017) use prototypes as a validation tool in their development of power-tools. Also, Matthiesen et al. (2016) utilize prototypes and early versions of the product to determine the different loads on the parts of the product when in use. Both have in common, that the prototypes are used to gain new insights about the product.

Those examples show, that the core activity and purpose of the broad spectrum of different approaches to prototyping is to gather information about the product in development and to learn about the product. For every prototype there are certain questions which developers try to find an answer to. Prototypes and the prototype testing phase can therefore be described as a means to the purpose of learning about the product.

\section{THE DETAILED PROCESS MODEL OF PROTOTYPING}

With the purpose of prototypes to support developers in their learning process, a process model for prototyping can be introduced. The detailed process model for prototyping is shown in Figure 3 and is based on the process model introduced by Heidemann (2001) which is explained above.

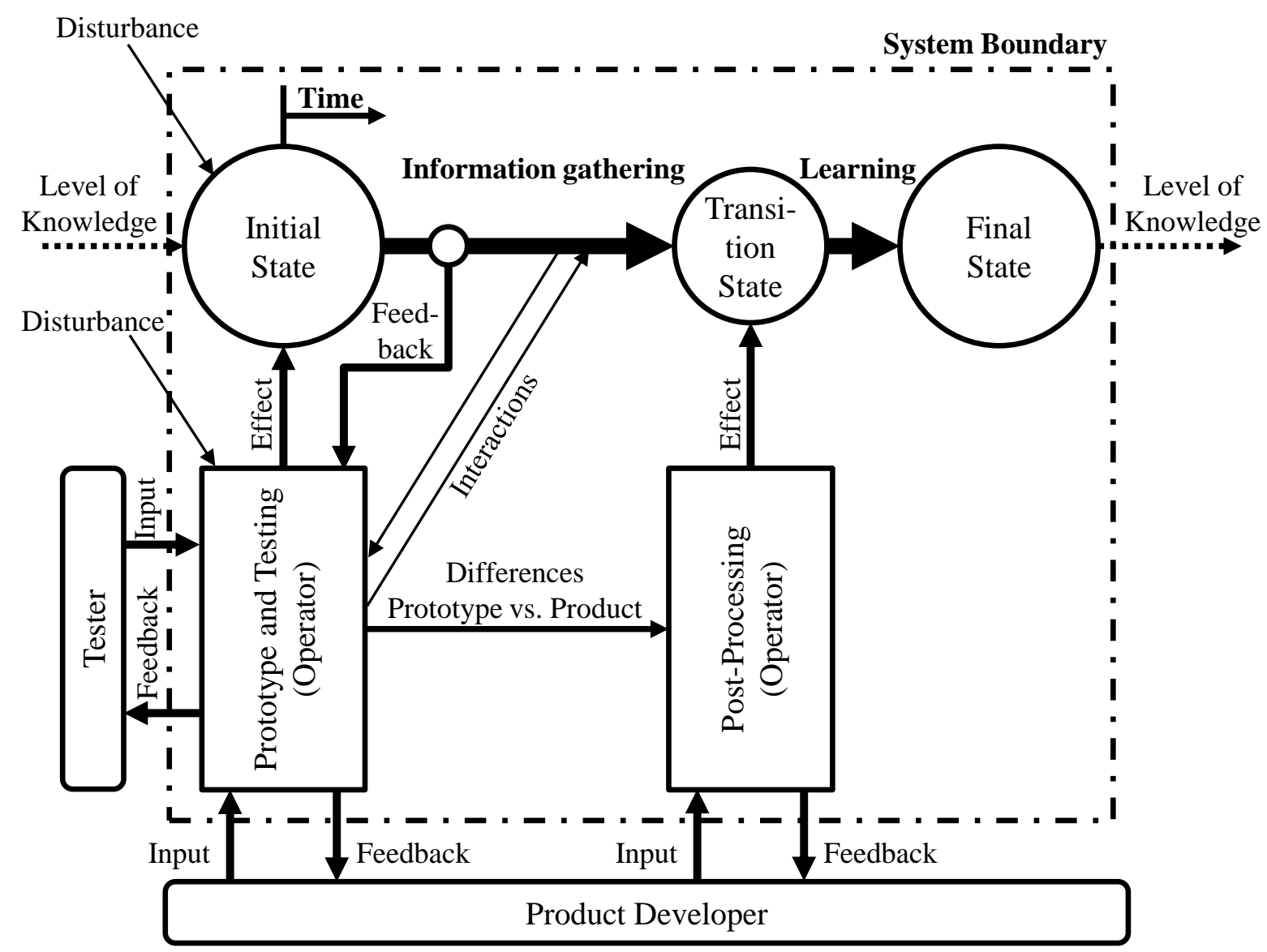

Figure 3. Detailed process model for the learning process using prototypes based on Heidemann (2001)

The model consists of a system boundary within which the learning process of the developers is described. This learning process however is split in two sub-processes, starting with the information gathering process followed by the actual learning process. The prototype and the respective testing phase are the means to the purpose of the developers, to learn about the product. Therefore, the prototype and the testing act as an operator. With learning being the overall process done, the initial state describes the level of knowledge of the product developers having open questions about the product. The prototype and the testing phase then have an effect on this initial state, starting the learning process. This learning process takes time and ultimately ends in the final state, which describes the level of knowledge of the product developers when 
having answered their questions. Product developers are the users of the prototype. Their inputs are on the one hand energy and resources to run the prototype and on the other hand the questions they have about the product. The prototype than affects the initial, unknowing state of the users with the results of the testing phase. While learning, some feedback from the learning process may affect the prototype and the testing. An example of such a feedback is when testers start to gain a better understanding of the prototype and how to use it. This may affect the way testers interact with the prototype. A practical example can be made in form of a prototype of a clutch with a different pedal characteristic compared to predecessor clutches. The main question may concern the durability of the clutch in a real world scenario but testers would first have to become accustomed with the differences in pedal characteristics before they are able to use the clutch as intended. There are also negative interactions between the learning process and the operator. When using the prototype to answer questions about the functionality of the product with the management as testers, a prototype which is far developed in terms of design may lead to discussions about details in the design rather than discussions about the functionality. Also Deininger et al. (2017) showed that there is an influence of the format of the prototype on the testers. One the one hand, the testing may be influenced negatively, in regards to testers not focussing on the functionality and therefore not challenging the functionality of the product under certain conditions and on the other hand the information gathering process is negatively influenced, when the feedback of the testers is not strongly related to the functionality, which was the main question. Comparable to the detailed process model of products, disturbances affect the initial state and the prototype. Disturbances on the initial state in this model may come in form of wrong assumptions about the product. With wrong assumptions, product developers may want to investigate questions which are not essential. Disturbances on the prototype and testing may occur in form influences of the test surroundings, which are not an intended part of the test. Note that there is a differentiation between the user and the tester. The user of the prototype is always the product developer who uses the prototype to answer questions. However, testers are the ones who directly interact with the prototype. Testers may consist of all stakeholders of the development process.

Compared to the detailed process model for products, the detailed process model for prototypes is expanded. This is because the testing with prototypes does not lead to the final state directly. When testing with the prototype, there is information gathered about the prototype. At this point it is essential to keep in mind, that the prototype is only a representation of the product which is altered to a certain degree. This is why the testing phase cannot answer the questions asked about the product directly but rather leads to a transition state, where information was gathered but has to be processed to lead to true answers. To reach the final state, product developers have to post-process the gathered information. For post-processing, the differences of the prototype and the product have to be analysed and factored in. Reaching the final state, product developers gain answers for the questions they asked about the product and are able to use them to further develop the product. With regards to the value of information discussed by Camburn et al. (2017), the value of the information in the transition state is comparably low and is drastically increased after the post-processing.

\section{EXAMPLE: PROTOTYPING UNDER HIGH AMBIGUITY}

To give an example of how the detailed process model can be used to describe a prototyping process, the prototyping process for a sensor-integrating elastic claw coupling is investigated. Schork et al. (2016) developed the concept and the prototype as a result of the search for new and simple ways of integrating sensor components in technical systems. With the idea of sensor-integrating machine elements, a subtype of mechatronic machine elements described by Martin et al. (2018), a broad application of sensor components is achievable. It is essential to mind that the goal of the integration of sensors in machine elements is not the monitoring of the state of the machine element itself, but rather to use the sensor data to gain information about the state of the whole technical system. This form of machine elements underlies a high amount of ambiguity, because of a lack of directly similar approaches. It is therefore highly recommended to build prototypes to learn about the different influencing factors on the different concepts especially in early stages of the development process, to determine the overall functional feasibility of the concept.

The concept of the sensor-integrating elastic claw coupling is based on the idea to measure the transferred torque of two shafts via the elastic coupling. The advantage of this concept compared to the alternative solution of using an additional torque measuring shaft is that the system and its parameters, such as the eigenfrequency, are not influenced. The design of the system therefore stays 
nearly untouched, leading to a simple integration of the torque measurement. Figure 4 shows the concept of the sensor-integrating elastic claw coupling on the left and the corresponding physical prototype on the right.
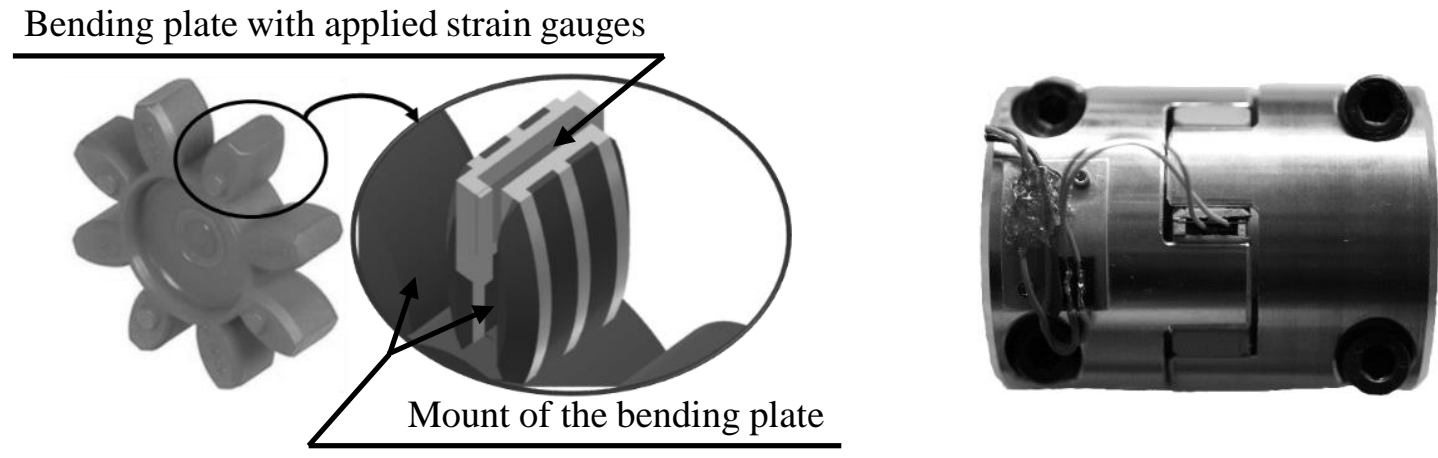

Figure 4. CAD-Model of the concept (left) and physical prototype of the sensor-integrating elastic claw coupling

The concept uses the distortion of the elastic element when torque is transferred via the coupling. To measure this distortion, one tooth of the elastic element of the coupling is substituted with an equally elastic measuring device. This device consists of a mounted bending plate with an applied strain gauge and a pressure piece. The distortion of the coupling causes the pressure piece to bend the bending plate, resulting in a measurable strain. With the measured strain and the properties of the bending plate, the distortion of the coupling is calculable. The distortion in combination with the torsional spring rate of the elastic claw coupling then lead to the amount of transferred torque.

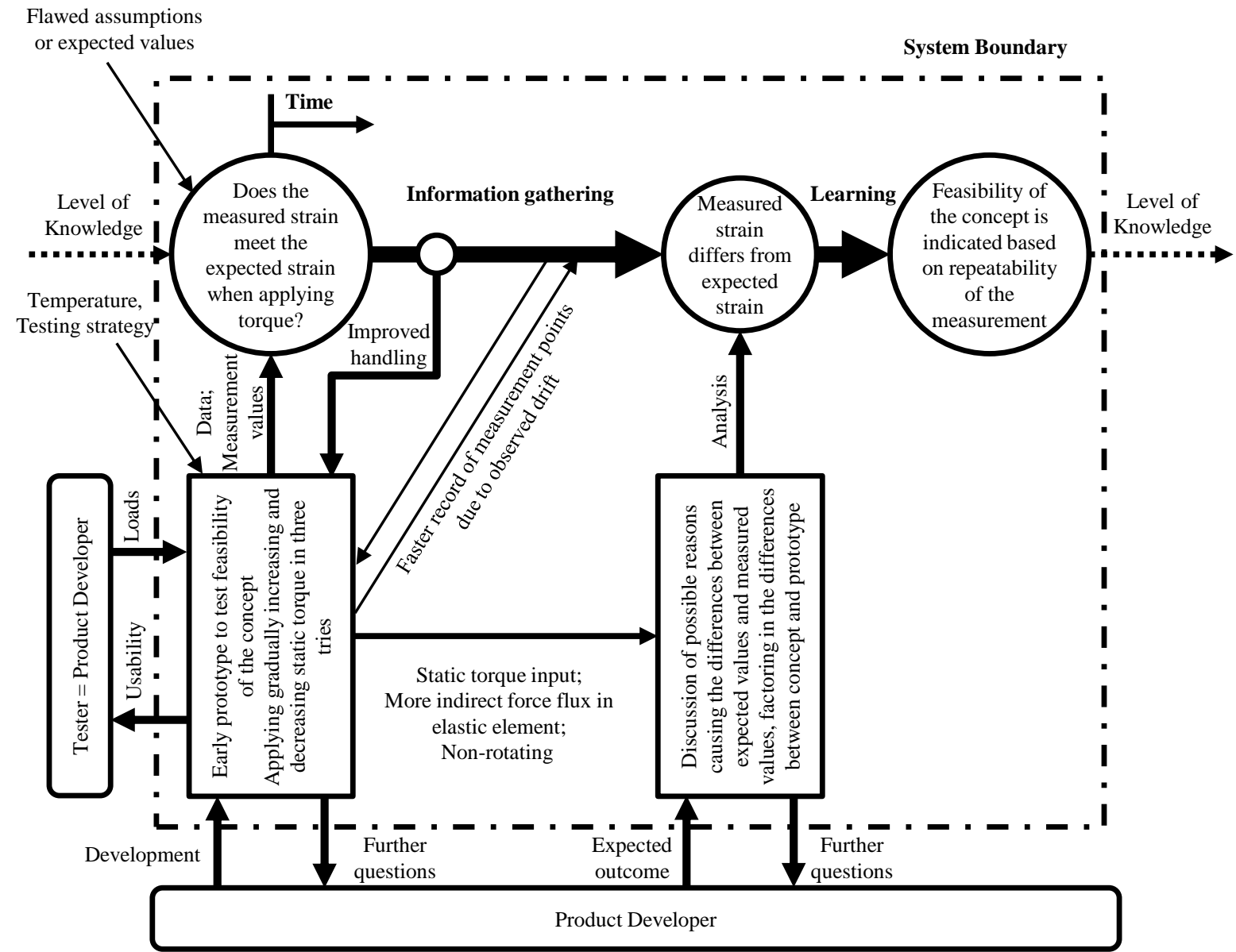

Figure 5. Detailed process model of the learning process while using the prototype of the sensor-integrating elastic claw coupling 
To gain new insights about the concepts, a prototype was developed. In this case, the task was to demonstrate the overall feasibility of the idea to measure the strain to gain information about the transferred torque. This represents the initial state in the detailed process model shown in Figure 5.

The prototype to answer this question went through a certain amount of changes in comparison to the concept of the product. First of all, the prototype is not intended to be used in a dynamic test rig. Instead, a static test rig is used in which the torque is applied via a lever in combination with weights. This deletes the necessity of a telemetric device to transfer the signals of the strain gauge to an analysis unit. The transfer is instead done via cables. Another change involves the geometry of the mount of the bending plate. The mount is simplified in a way that there is only a groove in the elastic element needed to fit the measuring device. In terms of changes however, it has to be noticed, that there now is no direct contact area between the metal part of the elastic claw coupling and the measuring device, leading to an indirect force flux.

For the prototype-testing, three tries were performed. The tester of the prototype is in this case the product developer. Each try consists of the installation of the coupling followed by an increase in torque from $0 \mathrm{Nm}$ to $56 \mathrm{Nm}$ and the decrease back to the starting point after which the coupling is removed. While testing the prototype, an improved handling was noticeable, which indicates the feedback of the learning process on the prototype testing. Furthermore, testing showed a drift of the sensor signal after a few seconds, leading to a faster recording of the measurement points by the tester. Figure 6 shows the results of this testing procedure. The graph shows the mean strain value of the three tries at each load while increasing or decreasing the load. The maximal standard deviation is $0,11 \mathrm{~mm}$ at $26 \mathrm{Nm}$, indicating a high repeatability of the measurement. Another important part to notice is the behaviour to up to around $10 \mathrm{Nm}$ of torque. In this area, there is no significant signal from the strain gauges, so there is no strain on the bending plate. When decreasing the weight, a hysteresis is observable.

In addition, the measured strain curves were compared to an analytical calculation of the estimated strain curve. To calculate the stain curve, the following equation was used.

$$
\varepsilon(T)=\frac{\sigma}{E}=\frac{M \cdot \frac{d}{2}}{E \cdot I}=\frac{F \cdot L \cdot \frac{d}{2}}{8 \cdot E \cdot I}=\frac{192 \cdot w(0,5 L) \cdot L \cdot \frac{d}{2}}{8 \cdot E \cdot I \cdot L^{3}}=\frac{24 \cdot r \cdot \frac{d}{2}}{c_{\varphi} \cdot L^{2}} \cdot T
$$

In this equation $w(0,5 L)$ describes the displacement at the centre of the bending plate with the length $L$ and the width $d$ which is equivalent to the distortion of the claw coupling. The distortion is calculated via the torsional spring rate $c_{\varphi}$ and the distance of the bending plate to the centre of the claw coupling $r$. This comparison is also shown in Figure 6. It is clear to see that there is a deviation between the estimated strain curve and the measured strain values. One the one hand, the quantitative values of strain are lower than the estimated values and on the other hand, the analytical calculation leads to a linear curve whereas the measured values have a progressive character.

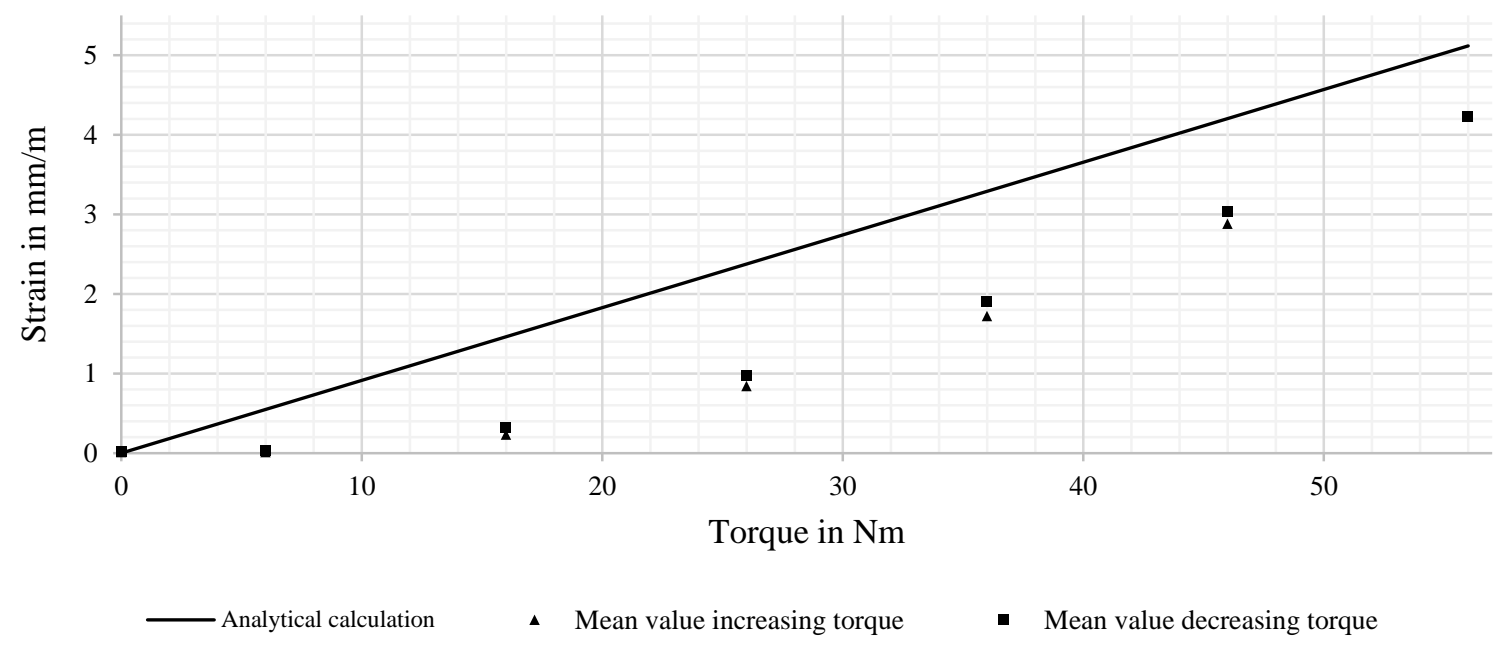

Figure 6. Measured strain of the bending plate compared to the analytical calculation

The measured values and the comparison to the analytical calculation of the strain curve lead the knowledge base of the product developers to the transition state. It was now the task of the product 
developers to post-process these information to finish the learning process When factoring in the changes between the concept and the prototype, the delay of $10 \mathrm{Nm}$ until the strain is measurable can be explained with the indirect contact of the claws of the coupling and the modified elastic element, leading to a free play which has to be overcome. In terms of repeatability and hysteresis, there are no significant changes identifiable, so this behaviour can be expected to come with the product as well.

Regarding the deviation between the measured strain curve and the analytical calculation of the strain curve, further post-processing has to be done, which is a feedback of the post-processing to the product developers in Figure 5. In this case, the reasons are not exclusively found in the physical prototype or the changes to the concept but rather in the analysis itself. The present analytical calculation was done with many simplifications based on a simple two-dimensional calculation method for a bending beam instead of using the calculation methods for plates. Furthermore, the torsional spring rate of the elastic claw coupling was presumed to be constant based on the manufacturer specifications, leading to a linear relation between applied torque and resulting increase in distortion. This is however due to further investigation, factoring in the material behaviour of the elastomer. The simplified analytical calculation is in the detailed process model describable as a disturbance on the initial state of knowledge of the developer, leading to inaccurate expectations about the behaviour of the prototype and also leading to unfavourable questions. Still, this disturbance and the therefore done comparison lead to new insights about the product in regards to possible calculation methods.

The final state of knowledge now describes the product designer having learned about the feasibility of the concept indicated by the measuring characteristics being qualitatively repeatable. In addition to that the occurring hysteresis and the differences of the expected and the measured strain curves need to be investigated.

\section{DISCUSSION, CONCLUSION AND FURTHER RESEARCH}

This paper introduces the detailed process model for prototyping depicting the learning process during prototyping. The model itself is strongly related to the detailed process model introduced by Heidemann (2001). The essential difference however is the two-stage character of the learning process when using prototypes consisting of an information gathering process and the actual learning process which is started by post-processing the gathered information of the prototype-testing. The model also depicts the influences and disturbances on the prototyping and testing as well as the different states of the learning process. Analysing the prototyping process during the development of the sensor-integrating elastic claw coupling showed that the learning process is describable with the postulated model, indicating its viability. Nevertheless, further validation with different cases has to be done to achieve a meaningful result. Further validation should also answer the question, if the process model is viable prior to the prototyping process. In this case, the model should be usable to identify disturbances and influences on the learning process, which can be used to determine requirements for the prototype. The use of this model may then lead to higher quality of requirements and an optimized amount of gained knowledge, referring to Figure 1. However, at this point the question of usability of the model to describe a planned prototyping process cannot be answered.

Regarding the research question in section 1.2 the introduced prototyping models based on product development models show, that certain product development models are applicable to the development of prototypes. This can be explained with the approach to differentiate the development process of products and prototypes mainly regarding the respective development task and the group of users. The detailed process model for prototyping describes the way product developers are learning with prototypes. Also, it visualizes the connections between the process of learning and the prototype and testing. This may be helpful in defining requirements for the prototype based on the goals of prototyping and the questions product developer have about the product in development. The holistic prototyping and process model depicts the development and the life cycle of the prototype and shows their connection. This can also be used to define requirements for prototyping as Schork and Kirchner (2018a) showed. Both models are examples to answer the research question indicating that other product development models may be used to describe prototype development processes by adjusting them based on different properties of the prototype development compared to the product development.

Further steps in this field of research consist on the one hand of the additional validation of the postulated detailed process model by studying different cases of prototyping processes and on the other hand of investigating the possibility to use the model as a tool in the development process of 
prototypes. To validate such a tool, it will be used in the further development of the sensor-integrating elastic claw coupling and other mechatronic machine elements. Furthermore, a deeper investigation into the general differences between a product and a prototype in terms of their development process shall be executed.

\section{REFERENCES}

Birkhofer, H., Anderl, R., Franke, H.-J., Großmann, J. and Pfouga, A. (2007), “Life Cycle Engineering”, in Krause, F.-L. (Ed.), Innovationspotenziale in der Produktentwicklung, Hanser, München, pp. 205-215.

Blessing, L. and Chakrabarti, A. (2009), DRM, a Design Research Methodology, Springer London, London.

Boehmer, A., Richter, C., Hostettler, R., Schneider, P., Plum, I., Böhler, D., Lindemann, U., Conradt, J. and Knoll, A. (2016), “Think.Make.Start. - An Agile Framework”, in Marjanović, D., Štorga, M., Pavković, N., Bojčetić, N. and Škec, S. (Eds.), Proceedings of the DESIGN 2016 14th International Design Conference, pp. 917-926.

Bursac, N., Rapp, S., Albers, A., Breitschuh, J. and Tanaiutchawoot, N. (2017), "Entscheidungsheuristiken in der PGE - Produktgenerationsentwicklung", in Krause, D., Paetzold, K. and Wartzack, S. (Eds.), DFX 2017: Proceedings of the 28th Symposium Design for X, pp. 275-286.

Camburn, B., Dunlap, B., Viswanathan, V., Linsey, J., Jensen, D. and Crawford, D. (2013), Connecting Design Problem Characteristics to Prototyping Choices to Form a Prototyping Strategy, ASEE Annual Conference, Atlanta.

Camburn, B., Viswanathan, V., Linsey, J., Anderson, D., Jensen, D., Crawford, R., Otto, K. and Wood, K. (2017), "Design prototyping methods. State of the art in strategies, techniques, and guidelines", Design Science, Vol. 3, p. 63.

Deininger, M., Daly, S., Sienko, K., Lee, J., Obed, S. and Effah Kaufmann, E. (2017), “Does Prototype Format Influence Stakeholder Design Input?”, in Maier, A., Škec, S., Kim, H., Kokkolaras, M., Oehmen, J., Fadel, G., Salustri, F. and van der Loos, M. (Eds.), Proceedings of the 21st International Conference on Engineering Design: VOLUME 6: Design Information and Knowledge, The Design Society, Glasgow, pp. 553-562.

Hallmann, M., Kunz, D., Schleich, B. and Wartzack, S. (2018), “Analyse anlagenspezifischer Fertigungseinflüsse auf die Genauigkeit FDM-gedruckter Bauteile”, in Krause, D., Paetzold, K. and Wartzack, S. (Eds.), DFX 2018: 29th Symposium on Design for X.

Heidemann, B. (2001), Trennende Verknüpfung: Ein Prozessmodell als Quelle für Produktideen, Zugl.: Darmstadt, Techn. Univ., Diss., 2001, Fortschritt-Berichte VDI Reihe 1, Konstruktionstechnik, Maschinenelemente, Vol. 351, Als Ms. gedr, VDI-Verl., Düsseldorf.

Leifer, L. and Steinert, M. (2014), "Dancing with ambiguity: Causality behavior, design thinking, and triple-looplearning”, in Gassmann, O. and Schweitzer, F. (Eds.), Management of the fuzzy front end of innovation, Springer International Publishing, Cham, pp. 141-158.

Martin, G., Schork, S., Vogel, S. and Kirchner, E. (2018), "MME - Potentiale durch mechatronische Maschinenelemente", Konstruktion, No. 01-02/2018, pp. 71-75.

Matthiesen, S., Gwosch, T., Mangold, S., Grauberger, P., Steck, M. and Cersowsky, S. (2017), "Frontloading in der Produktentwicklung von Power-Tools durch frühe Validierung mit Hilfe von leistungsskalierten Prototypen”, in Binz, H., Bertsche, B., Bauer, W., Spath, D. and Roth, D. (Eds.), Stuttgarter Symposium für Produktentwicklung SSP 2017: Stuttgart, 29. Juni 2017, Wissenschaftliche Konferenz, Universität Stuttgart.

Matthiesen, S., Gwosch, T., Schäfer, T., Dültgen, P., Pelshenke, C. and Gittel, H.-J. (2016), "Experimentelle Ermittlung von Bauteilbelastungen eines Power Tool Antriebsstrangs durch indirektes Messen in realitätsnahen Anwendungen als ein Baustein in der Teilsystemvalidierung", Forschung im Ingenieurwesen, Vol. 80 No. 1-2, pp. 17-27.

Menold, J., Jablokow, K. and Simpson, T. (2018), “The Prototype for X Framework. Assessing Impact on SelfReported Prototyping Behavior of Student Designers”, Journal of Mechanical Design.

Schork, S., Gramlich, S. and Kirchner, E. (2016), "Entwicklung von Smart Machine Elements - Ansatz einer smarten Ausgleichskupplung”, in Krause, D., Paetzold, K. and Wartzack, S. (Eds.), Design for X - Beiträge zum 27. DfX-Symposium Oktober 2016, TuTech Verlag TuTech Innovation GmbH, Hamburg, pp. 181-192.

Schork, S. and Kirchner, E. (2018a), "Defining Requirements in Prototyping: The Holistic Prototype and Process Development”, in Ekströmer, P., Schütte, S. and Ölvander, J. (Eds.), Proceedings of NordDesign 2018, NordDESIGN.

Schork, S. and Kirchner, E. (2018b), "Method for the Development of Early Prototypes of Mechatronic Machine Elements Based on their Crititcal Properties", in Marjanović, D., Štorga, M., Škec, S., Bojčetić, N. and Pavković, N. (Eds.), DS92: Proceedings of the DESIGN 2018 15th International Design Conference, essentials, pp. 1325-1336.

Ulrich, K.-T. and Eppinger, S.-D. (1995), Product design and development, International eds, McGraw-Hill, New York. 